\title{
Timing of amino acid-carbohydrate ingestion alters anabolic response of muscle to resistance exercise
}

\author{
KEVIN D. TIPTON, ${ }^{1,2}$ BLAKE B. RASMUSSEN, ${ }^{1,2}$ SHARON L. MILLER, ${ }^{1,2}$ STEVEN E. WOLF ${ }^{1}$ \\ SHARLA K. OWENS-STOVALL, ${ }^{1}$ BART E. PETRINI, ${ }^{1}$ AND ROBERT R. WOLFE ${ }^{1,2}$ \\ ${ }^{1}$ Department of Surgery, University of Texas Medical Branch, and ${ }^{2}$ Metabolism Unit, \\ Shriners Hospitals for Children, Galveston, Texas 77550
}

Received 5 September 2000; accepted in final form 6 March 2001

\begin{abstract}
Tipton, Kevin D., Blake B. Rasmussen, Sharon L. Miller, Steven E. Wolf, Sharla K. Owens-Stovall, Bart E. Petrini, and Robert R. Wolfe. Timing of amino acid-carbohydrate ingestion alters anabolic response of muscle to resistance exercise. Am J Physiol Endocrinol Metab 281: E197-E206, 2001.-The present study was designed to determine whether consumption of an oral essential amino acid-carbohydrate supplement (EAC) before exercise results in a greater anabolic response than supplementation after resistance exercise. Six healthy human subjects participated in two trials in random order, PRE (EAC consumed immediately before exercise), and POST (EAC consumed immediately after exercise). A primed, continuous infusion of L-[ring${ }^{2} \mathrm{H}_{5}$ ]phenylalanine, femoral arteriovenous catheterization, and muscle biopsies from the vastus lateralis were used to determine phenylalanine concentrations, enrichments, and net uptake across the leg. Blood and muscle phenylalanine concentrations were increased by $\sim 130 \%$ after drink consumption in both trials. Amino acid delivery to the leg was increased during exercise and remained elevated for the $2 \mathrm{~h}$ after exercise in both trials. Delivery of amino acids (amino acid concentration times blood flow) was significantly greater in PRE than in POST during the exercise bout and in the 1st $\mathrm{h}$ after exercise $(P<0.05)$. Total net phenylalanine uptake across the leg was greater $(P=0.0002)$ during PRE $(209 \pm 42$ $\mathrm{mg}$ ) than during POST $(81 \pm 19)$. Phenylalanine disappearance rate, an indicator of muscle protein synthesis from blood amino acids, increased after EAC consumption in both trials. These results indicate that the response of net muscle protein synthesis to consumption of an EAC solution immediately before resistance exercise is greater than that when the solution is consumed after exercise, primarily because of an increase in muscle protein synthesis as a result of increased delivery of amino acids to the leg.
\end{abstract}

muscle protein synthesis; muscle protein breakdown; stable isotopes; supplementation

BOTH EXERCISE AND NUTRITIONAL SUBSTRATES play important roles in muscle protein metabolism. An acute bout of resistance exercise increases muscle protein synthesis more than breakdown, so that net muscle protein balance (synthesis minus breakdown) is increased ( 5 , 19, 20). Hyperaminoacidemia at rest has similarly

Address for reprint requests and other correspondence: K. D. Tipton, Metabolism Unit, Shriners Hospital for Children, 815 Market St., Galveston, TX 77550 (E-mail: ktipton@utmb.edu). been demonstrated to increase net synthesis of muscle protein, primarily by stimulating muscle protein synthesis $(1,6)$. After intense resistance exercise, increased amino acid availability via intravenous infusion was shown to increase the rate of muscle protein synthesis above levels observed with amino acid infusion at rest (6). Thus exercise and amino acids seem to have complementary effects on muscle protein synthesis. Furthermore, the normal postexercise increase in muscle protein breakdown was attenuated when amino acids were infused after an exercise bout. Synthesis, in this case, exceeded breakdown, resulting in net muscle protein synthesis. Subsequently, we demonstrated that a solution of amino acids given orally was just as effective as intravenous amino acid infusion for developing net muscle protein synthesis after resistance exercise (27).

A combination of amino acids, to increase amino acid availability, and carbohydrates, to stimulate insulin release, should be a potent stimulator of net muscle protein synthesis. We recently demonstrated that ingestion of a bolus of $6 \mathrm{~g}$ of amino acids combined with $35 \mathrm{~g}$ of carbohydrates at both 1 and $3 \mathrm{~h}$ postexercise resulted in muscle protein anabolism (21). During an exercise bout, there may be a net loss of muscle protein, because protein synthesis is either decreased (8) or unchanged (9), whereas protein breakdown is generally considered to be elevated (22). Although muscle protein synthesis is increased after exercise, it appears that this response is not stimulated until some time after the exercise bout (17). Hyperaminoacidemia from ingestion of amino acids during the exercise bout, as opposed to after exercise, may counter the net loss of muscle protein, thereby creating a more favorable situation for muscle growth. The purpose of the present study was to determine whether ingesting a combination of amino acid and carbohydrate before exercise is more effective in stimulating net muscle protein synthesis than ingesting the mixture after exercise.

\footnotetext{
The costs of publication of this article were defrayed in part by the payment of page charges. The article must therefore be hereby marked "advertisement" in accordance with 18 U.S.C. Section 1734 solely to indicate this fact.
} 


\section{METHODS}

\section{Subjects}

Six healthy volunteers ( 3 females, 3 males) were studied in the postabsorptive state. The study design, purpose, and possible risks were explained to each subject before written consent was obtained. The Institutional Review Board and the General Clinical Research Center (GCRC) of the University of Texas Medical Branch at Galveston approved the study protocol. All subjects were healthy, nondiabetic, and normotensive. They had a normal cardiac rhythm with no abnormalities, as judged by medical history, physical examination, resting electrocardiogram, and laboratory blood and urine tests. Subjects were recreationally active and were instructed to refrain from physical exercise for $\geq 24 \mathrm{~h}$ before being studied. Mean $( \pm \mathrm{SE})$ age was $30.2 \pm 3.1 \mathrm{yr}$, height was $1.71 \pm 0.03 \mathrm{~m}$, weight was $66 \pm 6 \mathrm{~kg}$, body mass index was $22 \pm 1 \mathrm{~kg} / \mathrm{m}^{2}$, and leg volume was $9.78 \pm 0.61$ liters. At least $1 \mathrm{wk}$ before the initial infusion study, each subject was familiarized with the leg press and leg extension machine, and their one-repetition maximum (1RM, the maximum weight that can be lifted for one repetition) was determined on each. Mean 1RM for the leg press was $122.9 \pm 12.8 \mathrm{~kg}$ and for the leg extension was $92.3 \pm 13.7 \mathrm{~kg}$.

\section{Experimental Protocol}

The protocol was designed to determine whether an oral amino acid-carbohydrate solution (EAC) would be a more effective stimulator of muscle protein anabolism if given immediately before or immediately after a resistance exercise bout. Each subject participated in two trials in random order. The response of muscle protein metabolism was determined during and after an intense resistance exercise bout while each subject consumed, on separate occasions, a bolus of EAC immediately before exercise (PRE) or immediately after exercise (POST). Study days were separated by $\geq 2$ mo. Subjects were instructed to maintain a consistent dietary intake pattern throughout the duration of the study. One female subject completed only the PRE trial; thus all data reflect means of six subjects for PRE and five subjects for POST. A schematic representation of the study protocol is shown in Fig. 1.

\section{Study Protocol}

\section{A Muscle Biopsies \\ * AV Blood Sampling}

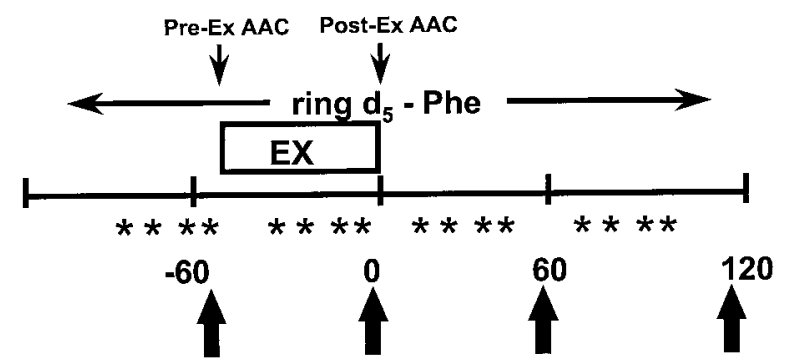

Fig. 1. Schematic representation of the study protocol. Time values are in minutes from the end of exercise. AV, arteriovenous; EX, exercise; EAC, essential amino acid-carbohydrate (supplement); ring $\mathrm{d}_{5}$-Phe, L- $\left[\right.$ ring $\left.^{2}{ }^{2} \mathrm{H}_{5}\right]$ phenylalanine.
Subjects reported to the GCRC on the evening before each study day and began fasting at 2200 . After the overnight fast, at $\sim 0600$, an 18-gauge polyethylene catheter was inserted into a large peripheral arm vein for the infusion of stable isotopic tracers of amino acids. Catheters were inserted in positions to prevent occlusion by bending of the arms. Subjects were subsequently transported to the Exercise Metabolism Laboratory in the Shriners Hospital for Children, Galveston. After background blood samples were taken, a primed, continuous infusion of $\mathrm{L}-\left[\right.$ ring $\left._{-}{ }^{2} \mathrm{H}_{5}\right]$ phenylalanine was started at $\sim 0630$ and continued throughout the protocol. The priming dose was $2 \mu \mathrm{mol} / \mathrm{kg}$, and the infusion rate was $0.05 \mu \mathrm{mol} \cdot \mathrm{min}^{-1} \cdot \mathrm{kg}^{-1}$. Catheters were then placed in the femoral artery and vein, as well as a second peripheral arm vein contralateral to the infusion site. The femoral arterial catheter was also used for the continuous infusion of indocyanine green (ICG).

After $2 \mathrm{~h}$ of infusion to establish an isotopic steady state, resting measurements were made of amino acid concentrations and enrichments in the femoral artery and vein, as well as muscle. Three blood samples, separated by $\sim 10 \mathrm{~min}$, were taken from the femoral artery and vein for the measurement of plasma arterial and venous amino acid enrichments and concentrations. Blood samples were immediately placed into preweighed tubes containing $1 \mathrm{ml}$ of sulfosalicylic acid per milliliter of blood and tubes containing lithium heparin. Leg blood flow was measured by the dye-dilution technique during this time (4). Briefly, ICG $(0.5 \mathrm{mg} / \mathrm{ml})$ was infused $(60$ $\mathrm{ml} / \mathrm{h}$ ) into the femoral artery. Blood samples were simultaneously taken from the femoral vein and a peripheral vein to measure ICG concentration. The ICG infusion was briefly halted and then quickly resumed to allow sampling from the femoral artery for isotopic measurements. Immediately after the blood sampling, a percutaneous muscle biopsy was taken from the vastus lateralis. Muscle biopsies were taken from the lateral portion of the vastus lateralis with sterile technique. The skin and subcutaneous tissue were anesthetized, and an $\sim 6-\mathrm{mm}$ incision was made in the skin and muscle fascia. A 5-mm Bergström biopsy needle (Depuy, Warsaw, IN), with the cutting window closed, was advanced $3-5 \mathrm{~cm}$ through the fascia deep into the muscle. With suction applied, the cutting cylinder was opened and then closed 2-3 times. A sample of $\sim 50 \mathrm{mg}$ of mixed muscle tissue was obtained with each biopsy. Each sample was quickly (within $1 \mathrm{~min}$ ) rinsed with ice-cold saline, blotted dry, and frozen in liquid $\mathrm{N}_{2}$.

Immediately after the first muscle biopsy, subjects performed an intense leg resistance exercise bout. Before initiation of the resistance exercise routine, subjects consumed either a 500-ml bolus of the EAC solution (PRE) or a placebo solution (POST). The exercise bout consisted of 10 sets of 8 repetitions of leg press at $80 \%$ of $1 \mathrm{RM}$ and 8 sets of 8 repetitions of leg extension at $80 \%$ of $1 \mathrm{RM}$. The rest interval between sets was $\sim 2 \mathrm{~min}$, and the entire exercise bout was completed in $\sim 45-50 \mathrm{~min}$. Blood samples were taken from the femoral artery and vein after the 4th and 8th sets of leg press ( $\sim 10$ and $20 \mathrm{~min}$ from the beginning of the exercise) and the 2nd and 8th, or final, sets of leg extension ( $\sim 30$ and $45 \mathrm{~min}$ from the beginning of the exercise). A second muscle biopsy was taken in the rest interval between the 7th and 8th sets of leg extension. A second bolus drink, placebo for the PRE trial and EAC for the POST trial, was consumed immediately after exercise and the final blood draw. A series of arterial and venous blood samples and two muscle biopsies were taken in the $2 \mathrm{~h}$ after exercise. Blood samples were drawn at 10,20,30, 45, 60, 90, and 120 min after exercise. 
Muscle biopsies were taken at $\sim 55$ and 115 min after exercise and the ingestion of the 2 nd bolus drink.

\section{EAC Solution}

Each subject consumed two 500-ml bolus drinks during each trial. The order of the trials was randomly selected. During the PRE trial, the EAC drink was consumed immediately before initiation of the exercise bout, and the placebo was consumed immediately upon cessation of the exercise bout. For the POST trial, the order was reversed. The EAC consisted of $6 \mathrm{~g}$ of essential amino acids, in amounts designed to increase muscle free intracellular amino acid levels in proportion to their respective requirements for protein synthesis, and $35 \mathrm{~g}$ of sucrose in $500 \mathrm{ml}$ of deionized-distilled water. The amounts of essential amino acids in a 500-ml bolus EAC solution were ( $\mathrm{mg}$ and $\mu \mathrm{mol}$, respectively) histidine $0.65,4.2$; isoleucine $0.60,4.6$; leucine $1.12,8.5$; lysine $0.93,6.4$; methionine $0.19,1.3$; phenylalanine $0.93,5.6$; threonine $0.88,7.4$; and valine $0.7,6.0$. Additionally, $0.0605 \mathrm{~g}$ of $\mathrm{L}-\left[\right.$ ring $\left.-{ }^{2} \mathrm{H}_{5}\right]$ phenylalanine was added to the solution to maintain isotopic steady state. A small amount of artificial sweetener, containing aspartame, was added to the EAC to improve palatability. The placebo solution was composed of deionized-distilled water and an artificial sweetener containing aspartame. The placebo contained $<200 \mathrm{mg}$ of phenylalanine.

\section{Analysis of Samples}

Blood. Amino acid enrichment and concentration of phenylalanine in whole blood were measured by gas chromatography-mass spectrometry (GC-MS; model 5989B, HewlettPackard, Palo Alto, CA) (18). Upon thawing, $500 \mu \mathrm{l}$ of the sulfosalicylic extract was passed over a cation exchange column (Dowex AG 50W-8X, 100-200 mesh H+ form; Bio-Rad Laboratories, Richmond, CA) and dried under vacuum using a Speed Vac (Savant Instruments, Farmingdale, NY). To determine the enrichment of infused amino acids in whole blood, the tert-butyldimethylsilyl ( $t$-BDMS) derivative of each amino acid was made according to previously described procedures $(5,18,19)$. Isotopic enrichments were determined by GC-MS (model 5989B, Hewlett-Packard) and expressed as a tracer-to-tracee ratio $(\mathrm{t} / \mathrm{T})(16)$. Concentrations of free amino acids were determined using an internal standard solution, as previously described $(4,5,18,19)$. The internal standard used was L-[ring- $\left.{ }^{13} \mathrm{C}_{6}\right]$ phenylalanine $(50 \mu \mathrm{mol} / \mathrm{l})$ added in a ratio of $\sim 100 \mu \mathrm{l} / \mathrm{ml}$ of blood. Because the tube weight was known, the amount of blood could also be determined, and the blood amino acid concentration was determined from the internal standard enrichments measured by GC-MS on the basis of the amount of blood and internal standard added (4, $5,18,19)$. Appropriate corrections were made for overlapping spectra that contributed to the $\mathrm{t} / \mathrm{T}$ (23). Additionally, $m+5$ enrichments were corrected $6 \%$ for contributions from $m+6$. Leg blood flow was determined by spectrophotometrically measuring the ICG concentration in serum from the femoral and the peripheral veins, as described previously $(4,5,19)$. Leg plasma flow was calculated from steady-state values of dye concentration and converted to blood flow by use of the hematocrit $(4,5,18)$. Plasma insulin levels were determined by radioimmunoassay (Diagnostic Products, Los Angeles, $\mathrm{CA}$ ). The intra-assay coefficient of variation (CV) was $1.45 \%$.

Muscle. Muscle biopsy tissue samples were analyzed for mixed protein-bound and free intracellular amino acid enrichment and concentration, as previously described $(4,5,18$, 19). Tissue biopsies ( $\sim 50 \mathrm{mg}$ ) of the vastus lateralis were immediately blotted and frozen in liquid $\mathrm{N}_{2}$. Samples were then stored at $-80^{\circ} \mathrm{C}$ until processed. Upon thawing, the $\sim 25-30 \mathrm{mg}$ of tissue were weighed and protein precipitated with $0.5 \mathrm{ml}$ of $10 \%$ perchloric acid. The tissue was then homogenized and centrifuged, and the supernatant was collected. This procedure was repeated two more times, and the pooled supernatant $(\sim 1.3 \mathrm{ml})$ was processed, as were the blood samples described above in Blood. To determine intracellular enrichment of infused tracers, the $t$-BDMS derivative was prepared as previously described $(4,5,19)$ and analyzed by GC-MS. Intracellular enrichment was determined by correction for extracellular fluid on the basis of the chloride method (2). Muscle free amino acid concentration was measured with the internal standard method, with corrections for the contribution of extracellular fluid and for overlapping spectra, as described previously $(4,5,18,19)$.

The remaining pellet of muscle tissue was further washed, twice with $0.9 \%$ saline and three times with absolute ethanol. It was then placed in an oven and dried at $50^{\circ} \mathrm{C}$ overnight. The dried pellet was then hydrolyzed at $110^{\circ} \mathrm{C}$ for $24 \mathrm{~h}$ with $6 \mathrm{~N} \mathrm{HCl}$. The protein hydrolysate was then passed over a cation exchange column and dried by Speed Vac derivatized with $t$-BDMS, as described in Blood. Enrichment of proteinbound $\mathrm{L}-\left[\right.$ ring $\left._{-}{ }^{2} \mathrm{H}_{5}\right]$ phenylalanine was determined by GC-MS (model 5973, Hewlett-Packard) with a splitless injection and positive electron impact ionization. Mass-to-charge ratios $(\mathrm{m} / z) 338$ and 341 were monitored. These ions are the $m+3$ and $m+5$ enrichments, respectively, where $m+0$ is the lowest molecular weight of the ion. The ratio of $m+5 / m+3$ was used because it is more sensitive than the traditional $m+5 / m+0$ (used for blood samples). Enrichment from the protein-bound samples was determined with a linear standard curve of known $m+5 / m+3$ ratios and corrected back to the absolute change in $m+5$ enrichment over the incorporation period.

\section{Calculations}

Chemical net amino acid balance (NB) across the leg was calculated from the difference between the femoral arterial and venous concentrations multiplied by the blood flow. Thus

$$
\mathrm{NB}=\left(\mathrm{C}_{\mathrm{a}}-\mathrm{C}_{\mathrm{v}}\right) \cdot \mathrm{BF}
$$

where $\mathrm{C}_{\mathrm{a}}$ is arterial amino acid concentration, $\mathrm{C}_{\mathrm{v}}$ is venous amino acid concentration, and $\mathrm{BF}$ is leg blood flow.

Area under the curve was used to calculate total, as well as essential and nonessential, amino acid uptake (mg) across the leg for a given time period. The resting value was used as baseline, so that all values reflected the uptake due to ingestion of EAC. The amount of phenylalanine that was taken up by the leg and utilized for protein synthesis was calculated by

$$
\mathrm{C}_{\mathrm{m} 4}-\mathrm{C}_{\mathrm{m} 1}=\mathrm{C}_{\mathrm{m} 4-\mathrm{m} 1}
$$

where $\mathrm{C}_{\mathrm{m} 4}$ and $\mathrm{C}_{\mathrm{m} 1}$ are the phenylalanine concentrations in the intracellular pool of the final (4th) and initial (1st) muscle biopsy. $\mathrm{C}_{\mathrm{m} 4-\mathrm{m} 1}$ is the amount of phenylalanine remaining in the muscle at the end of the study.

$$
\mathrm{C}_{\mathrm{m} 4-\mathrm{m} 1} \cdot \mathrm{LV} \cdot 0.6=\text { total Phe }
$$

where total Phe is the total amount of phenylalanine remaining in the leg at the end of the study, LV is leg volume, and 0.6 is the volume of leg that is muscle (10).

$$
\text { uptake }- \text { total Phe }=\text { Phe for MPS }
$$

where uptake is uptake of phenylalanine across the leg, and Phe for MPS is the amount of phenylalanine taken up by the leg and utilized for muscle protein synthesis.

Because phenylalanine is not metabolized in muscle, muscle protein synthesis and breakdown can be estimated using 
the NB across the leg and the arterial and venous enrichments of L- $\left[\right.$ ring $\left._{-}{ }^{2} \mathrm{H}_{5}\right]$ phenylalanine blood $(26,29)$. The rate of appearance $\left(\mathrm{R}_{\mathrm{a}}\right)$ and rate of disappearance $\left(\mathrm{R}_{\mathrm{d}}\right)$ of $\mathrm{L}$-[ring${ }^{2} \mathrm{H}_{5}$ ]phenylalanine were calculated as estimations of muscle protein breakdown and muscle protein synthesis, respectively, from plasma amino acids in the blood $(25,29)$

$$
\mathrm{R}_{\mathrm{a}}=\left(\mathrm{E}_{\mathrm{a}} / \mathrm{E}_{\mathrm{v}}-1\right) \cdot \mathrm{Ca} \cdot \mathrm{BF}
$$

where $\mathrm{E}_{\mathrm{a}}$ is arterial enrichment of $\mathrm{L}-\left[\right.$ ring $\left.-{ }^{2} \mathrm{H}_{5}\right]$ phenylalanine, $E_{v}$ is venous enrichment, and $R_{d}$ is $N B+R_{a}$.

$R_{a}, R_{d}$, and NB were calculated for four time periods by combining the individual measurements within each period and using the mean values in the calculations.

\section{Data Presentation and Statistical Analysis}

Data are presented as means \pm SE. Results across time for phenylalanine concentration were compared by one-way ANOVA, with significance set at $P<0.05$. When the overall $P<0.05$, Dunnett's post hoc test was used to detect individual differences between rest and each time point. Differences between PRE and POST for each time period and for total phenylalanine uptake were detected with Student's $t$-test with unpooled variances, with significance set at $P<0.05$.

Leg blood flow, phenylalanine enrichment, $R_{a}, R_{d}, N B$, delivery to the leg, and muscle concentration are presented as means of four periods: Rest, Exercise, Hour 1 Postexercise, and Hour 2 Postexercise. The model used to determine statistical differences for each of these variables (except for muscle concentration) is of the form

$$
Y_{s, \operatorname{Tr}, t}=\mathrm{S}_{s}+\sum_{j=1}^{3} A_{\mathrm{Tr}, t} t^{j}+\text { error }
$$

where $s$ is $1,2, \ldots, 6\left(\mathrm{~S}_{s}\right.$ is the effect of subject $\left.s\right), \operatorname{Tr}$ is $0,1(\mathrm{Tr}$ is the treatment, 0 is PRE, 1 is POST), $t$ (the time period) is $1,2,3$, or 4 .

For muscle concentration, the model (which requires deletion of the one subject who did not participate in the POST part of the study) is

$$
Y_{s, \operatorname{Tr}, t}=\mathrm{S}_{s, \operatorname{Tr}}+\sum_{j=1}^{3} A_{\mathrm{Tr}, t} t^{j}+\text { error }
$$

This change was made because of the apparently large change in baseline between PRE and POST studies for some of the subjects. The object of the analysis is to determine in which, if any, time periods $(t=1,2,3$, or 4$)$ the conditions

$$
\sum_{j=1}^{3} A_{0, t} t^{j} \neq \sum_{j=1}^{3} A_{1, t} t^{j}
$$

are satisfied, and for

$$
\operatorname{Tr}=0,1 \text { and } \tau
$$

which of the following hold

$$
\sum_{j=1}^{3} A_{\mathrm{Tr}, t} t^{j} \neq \sum_{j=1}^{3} A_{\mathrm{Tr}, \tau} \tau^{j}
$$

and in those cases to obtain some idea of the magnitudes of the change from the first to the second term. A general linear model program was run with the measured data to address these questions.

\section{RESULTS}

\section{Blood Phenylalanine Concentrations and Enrichments}

Ingestion of EAC resulted in significant hyperaminoacidemia in both the PRE and POST trials (Fig. 2). Mean phenylalanine concentration increased by $\sim 67 \%$ in the first $10 \mathrm{~min}$ of exercise and was significantly increased over resting levels by $10 \mathrm{~min}$ after exercise during the PRE trial. Phenylalanine concentration increased further after cessation of exercise and peaked $\sim 30$ min postexercise at levels $\sim 135 \%$ above basal. Phenylalanine concentration declined from 30 min postexercise until 120 min postexercise. During POST, mean phenylalanine concentration was unchanged during exercise, increased significantly at 20 min postexercise, peaked at $\sim 130 \%$ of resting values $30 \mathrm{~min}$ postexercise, and then declined steadily until $120 \mathrm{~min}$ postexercise.

Mean enrichments of L- $\left[\right.$ ring- $\left._{-}{ }^{2} \mathrm{H}_{5}\right]$ phenylalanine are presented as means of the four time periods in Table 1. Arterial enrichment was decreased from rest during exercise in both trials and in the 2 nd $h$ postexercise in POST. Arteriovenous difference in enrichments was decreased during exercise during both trials and during the 1st $h$ after exercise during PRE.
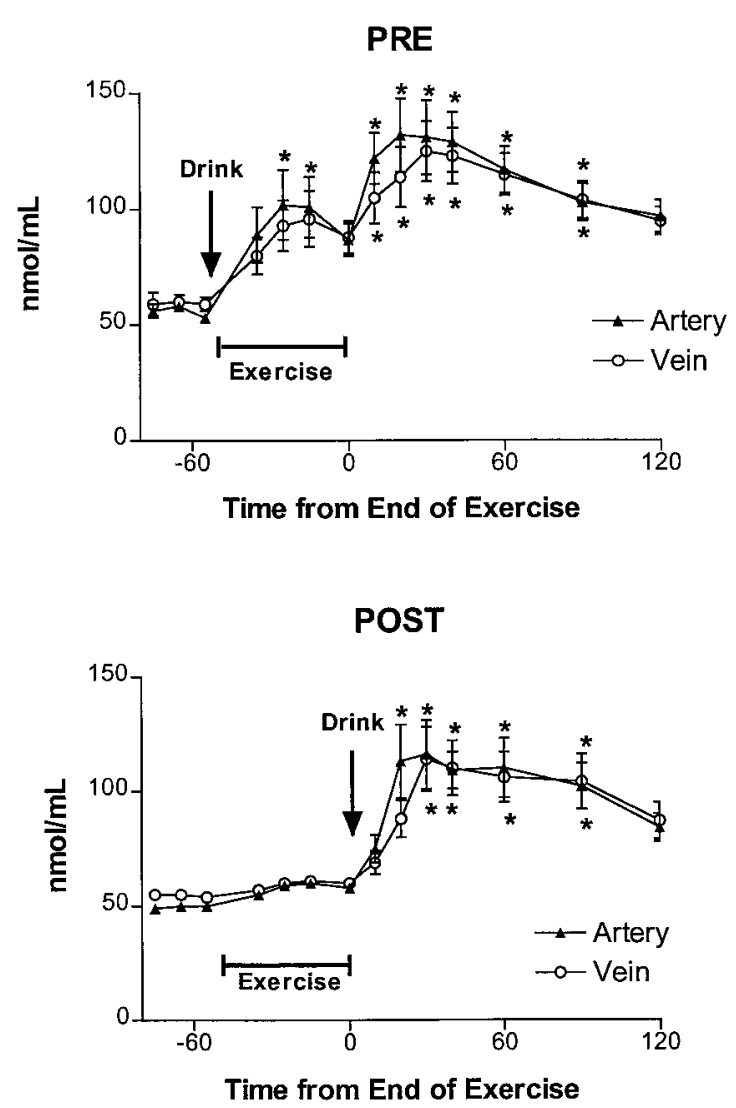

Fig. 2. Arterial and venous phenylalanine concentrations over time for PRE trial (EAC before exercise, top) and POST trial (EAC after exercise, bottom). *Significantly different from resting levels (time $-55), P<0.05$. 
Table 1. Mean arterial and venous phenylalanine enrichments and arteriovenous difference in enrichments in PRE and POST trials

\begin{tabular}{llccrr}
\hline \hline & & Rest & Exercise & 1 H Post-Ex & 2 H Post-Ex \\
\hline Artery & PRE & $0.0884 \pm 0.0134$ & $0.0724 \pm 0.0084^{*}$ & $0.0691 \pm 0.0092$ & $0.0759 \pm 0.0126$ \\
& POST & $0.0886 \pm 0.0165$ & $0.0687 \pm 0.0108^{*}$ & $0.0664 \pm 0.0117$ & $0.0691 \pm 0.121^{*}$ \\
Vein & PRE & $0.0655 \pm 0.0087$ & $0.0680 \pm 0.0078$ & $0.0641 \pm 0.0079$ & $0.0667 \pm 0.0092$ \\
& POST & $0.0656 \pm 0.0118$ & $0.0643 \pm 0.0099$ & $0.0598 \pm 0.0106$ & $0.0601 \pm 0.0100$ \\
a-v Difference & PRE & $0.0151 \pm 0.0072$ & $0.0044 \pm 0.0011^{*}$ & $0.0054 \pm 0.0018^{*}$ & $0.0092 \pm 0.0038$ \\
& POST & $0.0230 \pm 0.0049$ & $0.0044 \pm 0.0010^{*}$ & $0.0067 \pm 0.0011$ & $0.0090 \pm 0.0022$ \\
\hline
\end{tabular}

Values are enrichments $\pm \mathrm{SE}$, expressed as tracer-to-tracee ratio (t/T). a-v, arteriovenous; PRE, value when essential amino acidcarbohydrate (EAC) drink was consumed before exercise. POST, value when EAC was consumed after exercise. Rest, mean value for resting time period. Exercise, mean value during exercise bout. $1 \mathrm{H}$ Post-Ex, mean value for samples taken $0-60$ min after exercise bout. $2 \mathrm{H}$ Post-Ex, mean value for samples taken 60-120 min after exercise bout. * Significantly different from Rest, $P<0.05$.

\section{Muscle Phenylalanine Concentrations}

Muscle intracellular free phenylalanine concentrations are summarized in Fig. 3. Phenylalanine concentrations in muscle were significantly greater at rest during the PRE trial than during POST. During PRE, muscle phenylalanine concentration was increased $46 \%$ by the end of exercise and was further increased to 86\% above basal levels $1 \mathrm{~h}$ after exercise. Two hours after exercise, and thus $3 \mathrm{~h}$ after ingestion of EAC, muscle phenylalanine concentrations were $65 \%$ above basal. During POST, muscle phenylalanine concentrations were not increased during exercise but were significantly elevated above rest and exercise levels at $2 \mathrm{~h}$ postexercise, i.e., $2 \mathrm{~h}$ after ingestion of $\mathrm{EAC}$, respectively. When the differences in resting values are accounted for, muscle phenylalanine concentration was not significantly different between PRE and POST at any time point.

\section{Blood Flow and Phenylalanine Delivery to the Muscle}

Blood flow to the leg at rest was not different between treatments (Table 2). Resistance exercise significantly increased leg blood flow by $\sim 324 \%$ during PRE and by $\sim 201 \%$ during POST. In the 1 st $\mathrm{h}$ after exercise, leg blood flow was still significantly elevated above rest during both trials, but there was no difference from rest during the $2 \mathrm{nd} h$. During exercise and in the 1 st $\mathrm{h}$ after exercise, leg blood flow was significantly greater for PRE than for POST.

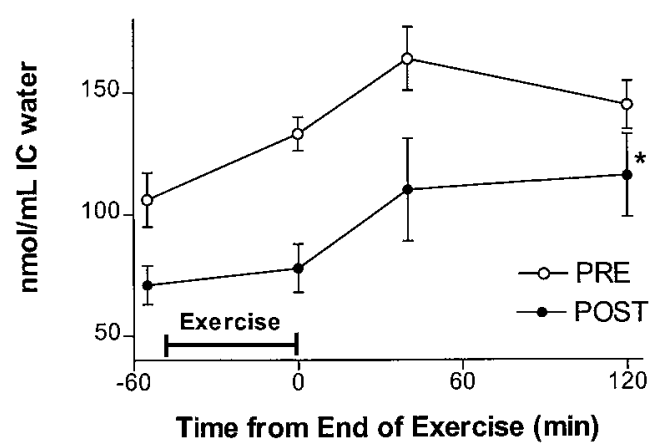

Fig. 3. Muscle free intracellular concentration (IC) of phenylalanine for 4 muscle biopsies during PRE and POST trials. *Significantly different from biopsy 1 (rest), $P<0.05$.
Amino acid delivery to the leg $\left(\mathrm{C}_{\mathrm{a}} \times \mathrm{BF}\right)$ at rest was not significantly different between trials (Table 2). During exercise, delivery was increased by $\sim 650 \%$ in the PRE trial and by almost $250 \%$ in the POST trial. Delivery remained elevated above resting levels during the $1 \mathrm{st} \mathrm{h}$ after exercise for both trials but was not increased in the $2 \mathrm{nd} \mathrm{h}$ postexercise. Phenylalanine delivery to the muscle was greater in PRE than POST during exercise and the $1 \mathrm{st} \mathrm{h}$ after exercise.

\section{Plasma Insulin}

Arterial insulin values for each time period are shown in Table 3. Insulin levels significantly increased after EAC consumption in each trial, i.e., during exercise for PRE and immediately after exercise for POST. Insulin remained elevated during the 1 st $\mathrm{h}$ postexercise in PRE and returned to resting levels by the $2 \mathrm{nd} h$ postexercise in both trials.

\section{Phenylalanine Uptake Across the Leg}

Figure 4 shows the net phenylalanine uptake across the leg measured over $3 \mathrm{~h}$ for the PRE and POST trials. Net uptake of phenylalanine was $\sim 160 \%$ greater in PRE than in POST during the entire $3 \mathrm{~h}$. The percentage of ingested phenylalanine that was taken up by the leg was almost threefold greater $(P=0.01)$ during PRE $(21 \pm 4 \%)$ than during POST $(8 \pm 2 \%)$, or $42 \pm 8$ vs. $16 \pm 4 \%$ for PRE vs. POST, respectively, for both legs. More phenylalanine remained in the muscle intracellular pool of the leg at the end of the study in POST than in PRE $(P=0.04 ; 24 \pm 3$ and $42 \pm 8$ for PRE and POST, respectively). Thus, over the $3 \mathrm{~h}$ of the study, $180 \pm 50 \mathrm{mg}$ of phenylalanine were taken up and incorporated into protein during PRE and $39 \pm 18 \mathrm{mg}$ during POST $(P=0.02)$.

When these values are calculated for only the final $2 \mathrm{~h}$ of each trial, the differences narrow from the full $3 \mathrm{~h}$ and do not reach statistical significance, but the trend for PRE values to be greater than POST remains. Phenylalanine uptake for only the $2 \mathrm{~h}$ postexercise was $243 \pm 120 \mathrm{mg}$ phenylalanine for PRE and $130 \pm 45 \mathrm{mg}$ phenylalanine for POST $(P=0.19)$. The mean percentage of ingested phenylalanine taken up by one leg in the final $2 \mathrm{~h}$ postexercise only was $80 \%$ greater during PRE $(25 \pm 12 \%)$ than during POST $(13 \pm 5 \% ; P=$ 
Table 2. Mean blood flow and delivery of phenylalanine to the leg for PRE and POST trials

\begin{tabular}{|c|c|c|c|c|c|}
\hline & & Rest & Exercise & 1 H Post-Ex & 2 H Post-Ex \\
\hline \multirow[t]{2}{*}{ Blood flow, $\mathrm{ml} \cdot \mathrm{min}^{-1} \cdot 100 \mathrm{ml} \mathrm{LV}-1$} & PRE & $4.59 \pm 0.58$ & $19.46 \pm 2.24^{*}$ & $7.64 \pm 1.73^{*}$ & $5.14 \pm 0.74$ \\
\hline & POST & $3.67 \pm 0.46$ & $11.05 \pm 1.28 * \dagger$ & $4.72 \pm 0.36^{* \dagger}$ & $3.35 \pm 0.32$ \\
\hline \multirow[t]{2}{*}{ Phe delivery, $\mathrm{nmol} \cdot \min ^{-1} \cdot 100 \mathrm{ml} \mathrm{LV}-1$} & PRE & $253 \pm 32$ & $1,890 \pm 396^{*}$ & $828 \pm 129^{*}$ & $539 \pm 80$ \\
\hline & POST & $191 \pm 28$ & $654 \pm 80 * \dagger$ & $506 \pm 97 * \dagger$ & $341 \pm 59$ \\
\hline
\end{tabular}

Values are means \pm SE. Delivery of phenylalanine to the leg is calculated by blood flow $\times$ arterial concentration. LV, leg volume. $*$ Significantly different from Rest, $P<0.05$. † Significantly different from corresponding PRE value, $P<0.05$.

0.20). Similarly, the mean amount of phenylalanine taken up during the final $2 \mathrm{~h}$ after EAC ingestion (i.e., during exercise and the $1 \mathrm{st} \mathrm{h}$ after exercise for PRE and the $2 \mathrm{~h}$ after exercise for POST) in each trial was $195 \pm 37 \mathrm{mg}$ for PRE and $130 \pm 45$ for POST, $P=0.14$.

\section{Phenylalanine Kinetics}

Figure 5 summarizes phenylalanine $R_{\mathrm{a}}, \mathrm{R}_{\mathrm{d}}$, and NB for each time period during PRE and POST trials. Phenylalanine $R_{a}$ did not change significantly from resting levels during or after exercise in either PRE or POST. PRE and POST $R_{a}$ values were not statistically different at any time point. $R_{d}$ increased from Rest in the hour immediately after EAC consumption by $216 \%$ during PRE (exercise) and by $60 \%$ during POST (1st h after exercise) trials. PRE $R_{d}$ was significantly greater than POST $R_{d}$ during exercise and in the $1 \mathrm{st} h$ after exercise. $R_{d}$ was not different for PRE and POST in the 2nd $\mathrm{h}$ after exercise.

During PRE, NB changed from negative at rest to positive values during exercise and the 1 st $h$ postexercise. During POST, NB was negative at rest and during exercise but increased to positive values after exercise, when the EAC drink was consumed. NB during POST immediately returned to zero in the $2 \mathrm{nd} h$ after exercise. NB was significantly greater during exercise and in the 1st $h$ after exercise in the PRE trial than in the POST trial.

\section{DISCUSSION}

This study was designed to determine whether the response of muscle protein metabolism to an EAC solution was different if consumed immediately before resistance exercise rather than immediately after resistance exercise. Ingestion of EAC changed net muscle protein balance from negative values, i.e., net release, to positive net uptake, in both trials. However, the total response to the consumption of EAC immediately before exercise was greater than the response when

Table 3. Mean arterial insulin levels during 4 time periods for PRE and POST trials

\begin{tabular}{lcrcc}
\hline \hline & Rest & Exercise & 1 H Post-Ex & 2 H Post-Ex \\
\hline PRE & $4.5 \pm 0.5$ & $18.5 \pm 5.7$ & $22.0 \pm 6.2$ & $6.2 \pm 2.0$ \\
POST & $4.1 \pm 0.8$ & $8.5 \pm 2.4$ & $27.0 \pm 5.8$ & $6.6 \pm 1.2$ \\
\hline
\end{tabular}

Values are means $\pm \mathrm{SE}$, expressed in IU/ml. Both PRE and POST were significantly different across time, but individual significant differences were not identifiable.
EAC was consumed immediately after exercise. Furthermore, it appears that the change from a catabolic state in the muscle to an anabolic state was primarily due to an increase in muscle protein synthesis.

In the present study, the effectiveness of the drink appeared to be greater when it was consumed immediately before exercise (PRE) compared with immediately after exercise (POST). Approximately $209 \pm 42$ $\mathrm{mg}$ of phenylalanine were taken up across the leg in the PRE trial, whereas only $81 \pm 19 \mathrm{mg}$ of phenylalanine were taken up during POST. Whereas the response of muscle protein metabolism increased dramatically and then declined within $1 \mathrm{~h}$ to basal levels after EAC consumption in the POST trial, the response was sustained in the PRE trial. Net balance increased during exercise, declined slightly, and then increased a second time after exercise when the drink was consumed before exercise. The length of the effect, plus higher blood flow during exercise in the PRE trial, resulted in significantly greater total uptake over the entire study period.

In this study, the primary end point was to examine the impact of the timing of EAC ingestion in relation to resistance exercise on net muscle protein synthesis and, as a result, the accretion of muscle. Thus the response over the entire 3 -h study period is the most appropriate to compare between trials. On the other hand, it could be argued that the results are biased toward the PRE trial by calculating the data over the entire 3 -h study period. During PRE, the entire $3 \mathrm{~h}$ follows the consumption of EAC, whereas during POST, only 2 of the $3 \mathrm{~h}$ follow EAC ingestion. As a result, we also calculated the uptake across the leg over only the final $2 \mathrm{~h}$ after exercise of each trial, i.e., the 2 nd and 3rd $h$ after EAC ingestion during PRE and the 1st and 2nd h after EAC ingestion during POST. Calculated this way, the gap between the trials narrowed, but the mean uptake across the leg was still

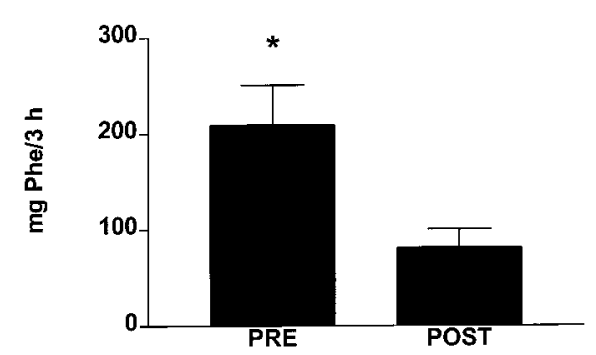

Fig. 4. Net phenylalanine uptake across the leg over $3 \mathrm{~h}$ for PRE and POST trials. *Significantly different from POST $(P=0.013)$. 
$\mathrm{Ra}$ of Phenylalanine

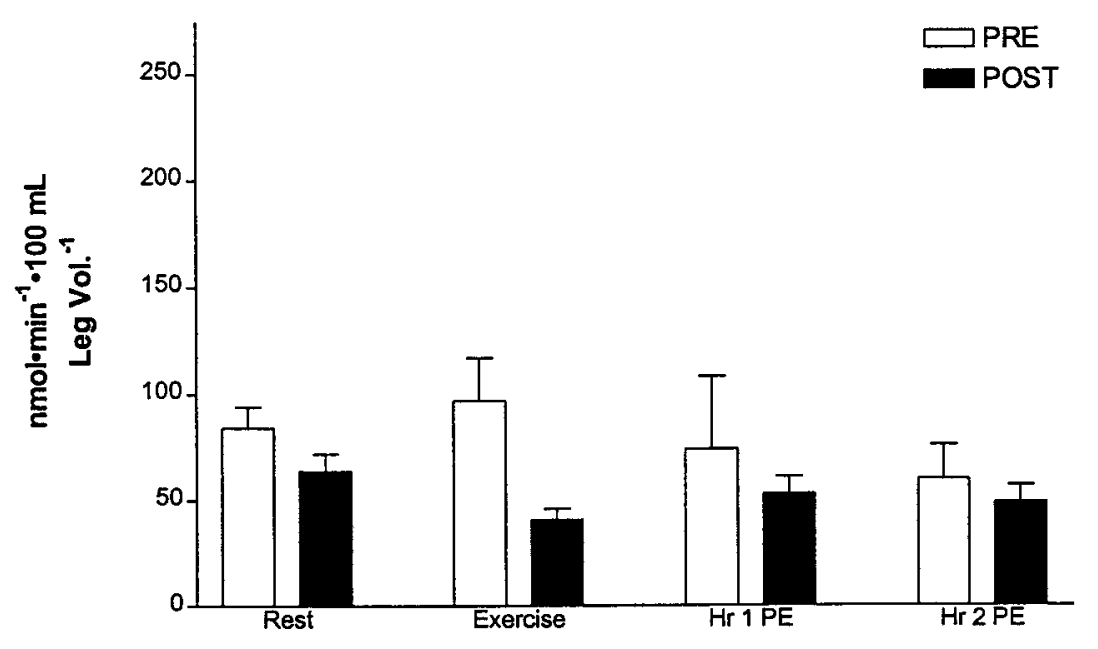

Rd of Phenylalanine

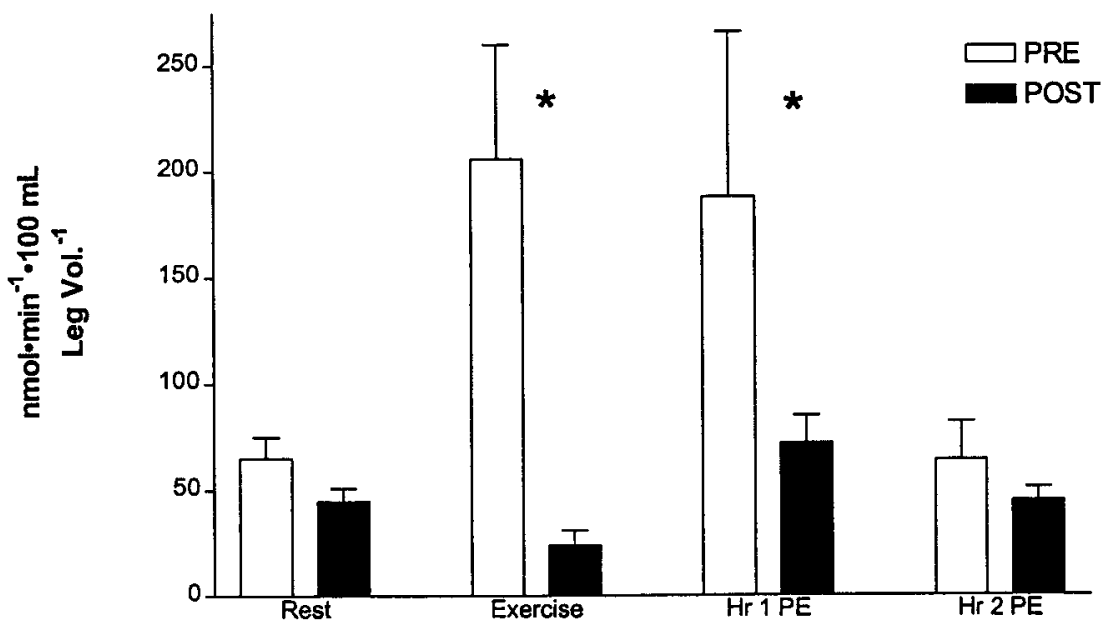

NB of Phenylalanine

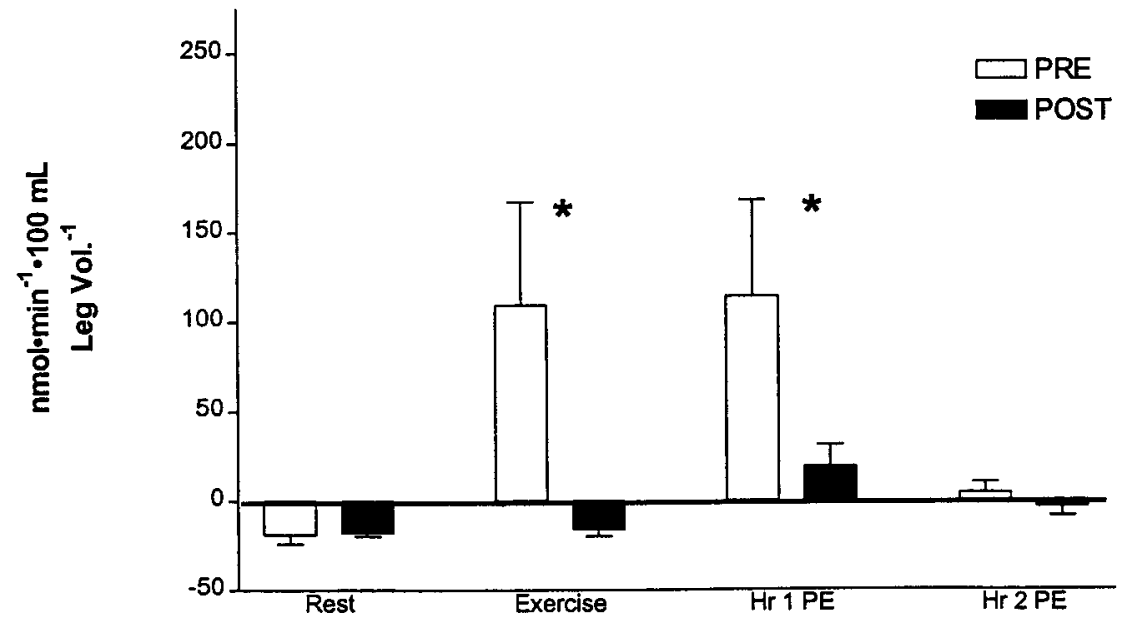

Fig. 5. Muscle phenylalanine rate of appearance from muscle $\left(R_{\mathrm{a}}\right)$, phenylalanine uptake from blood $\left(R_{d}\right)$, and net phenylalanine balance across leg (NB) for 4 time periods during PRE (open bars) and POST (solid bars). Rest, mean of 3 resting values. $\mathrm{Ex}$, mean of 4 samples taken during resistance exercise. Hr $1 \mathrm{PE}$, mean of 4 samples taken during the $1 \mathrm{st} \mathrm{h}$ after exercise. Hr $2 \mathrm{PE}$, mean of 3 samples taken during the 2 nd $\mathrm{h}$ after exercise. *PRE significantly different from POST, $P<0.05$.
$80 \%$ greater for PRE than for POST $(244 \pm 120 \mathrm{mg}$ vs. $130 \pm 45 \mathrm{mg}$, respectively), although the difference did not reach statistical significance $(P=0.09)$. If anything, comparing only the final $2 \mathrm{~h}$ of each trial biases the results toward favoring the POST trial, because the 1 st $h$ after consumption of EAC during PRE is ignored. Nonetheless, it is still evident that consuming EAC before exercise is more effective than after exercise. 
Effectiveness of the timing of EAC ingestion is supported by comparing the amount of phenylalanine taken up by the leg to the amount ingested in each trial. During PRE, $\sim 21 \%$ of ingested phenylalanine was taken up by the leg, thus $\sim 42 \%$ by both legs. The proportion was much lower during POST, $\sim 8 \%$ across one leg or $16 \%$ for both legs. When EAC was consumed $1 \mathrm{~h}$ after exercise, $\sim 125 \mathrm{mg}$ of phenylalanine were taken up across the leg (21), or about one-half of the value found when EAC was consumed before exercise. This represented $\sim 11 \%$ of the ingested phenylalanine for one leg, or $22 \%$ for both legs. When amino acids were infused over a 3 -h period after exercise, $\sim 34 \%$ of the infused amino acids were taken up across both legs (6). Clearly, EAC consumption before exercise is more effective than after exercise.

These data do not allow us to determine definitively the reasons for the greater response of net muscle protein synthesis to consuming essential amino acids plus carbohydrates immediately before exercise rather than after exercise. However, it is likely that the greater delivery of amino acids to the muscle during PRE accounts for the greater net uptake than during POST. During exercise in the POST trial, net muscle protein balance, as well as phenylalanine $R_{d}$, an index of muscle protein synthesis, was unchanged, whereas in the PRE trial, phenylalanine $R_{d}$ and NB were increased. Consuming a source of amino acids before exercise increases amino acid availability. Providing amino acids at a time when blood flow is elevated, such as during the exercise bout, maximizes delivery to the muscle. Previous studies have demonstrated that muscle protein synthesis is related to amino acid delivery to the leg $(5,6,27)$. Phenylalanine delivery during exercise in the PRE trial was increased 6.5-fold over resting levels and was more than twice that of POST. Furthermore, delivery remained elevated after exercise during PRE to a significantly greater extent above that during POST. Similarly, in our previous study, amino acid delivery was increased by EAC ingestion at both 1 and $3 \mathrm{~h}$ postexercise (21) to levels comparable to those obtained when EAC was consumed immediately after exercise. Thus consumption of amino acids before exercise results in greater amino acid delivery than when they are consumed at various time points after exercise, likely accounting for the greater response of net muscle protein synthesis demonstrated during the PRE trial.

Previously, we showed that hyperaminoacidemia elicited by intravenous infusion of mixed amino acids (6) and oral ingestion of both mixed and essential amino acids (27) resulted in net muscle protein synthesis after resistance exercise. In these studies, $\sim 40 \mathrm{~g}$ of amino acids were provided steadily over a 3 -h period. We also demonstrated that nonessential amino acids are unnecessary to stimulate net muscle protein synthesis at rest (28) or after exercise (27). Subsequently, we examined the response of muscle protein metabolism to ingestion of a smaller amount of essential amino acids plus carbohydrates (21) identical to the one used in the present study. Similar levels of net muscle protein synthesis resulted when subjects consumed the bolus amino acid-carbohydrate solution at both 1 and $3 \mathrm{~h}$ after exercise (21). Taken together with the present results, it is clear that a relatively small amount of essential amino acids, combined with carbohydrates, is a potent stimulator of net muscle protein synthesis when given either before or at various times after resistance exercise.

It is not possible to delineate the effectiveness of the separate components of the drink from this study. We have previously demonstrated that muscle protein synthesis is stimulated by essential amino acids alone (27, 28). Even single essential amino acids in a flooding dose may stimulate muscle protein synthesis (24). It is more difficult to assign a role to insulin in the change from net negative protein balance to positive protein balance. After exercise, insulin seems to be necessary for protein synthesis to occur $(11,12,14)$, yet increased insulin does not stimulate muscle protein synthesis (7). However, elevated insulin after resistance exercise does diminish the increase of muscle protein breakdown in response to exercise (7). Consistent with this notion, during the present study, phenylalanine $R_{a}$, an index of muscle protein breakdown, did not increase after exercise in either trial. Thus stimulation of muscle protein synthesis by essential amino acids, in addition to inhibition of the normal postexercise rise in breakdown, likely accounts for the effectiveness of the EAC drink for stimulating net muscle protein synthesis after resistance exercise.

Determination of the response of the muscle in the present study is based primarily on uptake of phenylalanine across the leg. It is assumed that phenylalanine uptake corresponds to accretion of muscle protein. However, it is possible that all of the amino acids taken up by the muscle are not incorporated into protein, but instead some fraction of the uptake simply expands the muscle free intracellular pool. The amino acids could then be released at some time after the conclusion of the measurements, without ever being utilized for muscle protein synthesis. Thus it is possible that net uptake overestimated the extent of net muscle protein synthesis. However, even if we assume the unlikely circumstance that all of the phenylalanine remaining in the muscle intracellular pool at the conclusion of the study would be subsequently released, the amount does not appear to be a substantial proportion of that taken up by muscle, especially in the PRE trial. During PRE, $24 \pm 3 \mathrm{mg}$ of phenylalanine were taken up by muscle but not utilized for protein synthesis, in contrast to $42 \pm 8 \mathrm{mg}$ during POST. Thus the total amount of phenylalanine taken up by the leg and utilized for protein synthesis was $\sim 180 \mathrm{mg}$ ( $\sim 86 \%$ of total uptake) during PRE and $\sim 39 \mathrm{mg}$ ( $\sim 48 \%$ of total uptake) during POST. Clearly, even with this conservative estimate, a large proportion of the phenylalanine taken up by muscle was, in fact, utilized for muscle protein synthesis during the study, further supporting the notion that the EAC solution is an effective stimulator of muscle protein anabolism. 
In the fasted state, muscle protein breakdown exceeds muscle protein synthesis, resulting in a net negative muscle protein balance. Net positive muscle protein balance can result only from an increase in muscle protein synthesis and/or a decrease in muscle protein breakdown. Resistance exercise alone has been shown to increase muscle protein synthesis, but breakdown is also increased, such that net muscle protein balance remains negative (5). Additionally, net muscle protein synthesis as a consequence of hyperaminoacidemia after resistance exercise is primarily due to increased muscle protein synthesis $(6,27)$. In our previous study, increased muscle protein synthesis was responsible for the change from a catabolic to an anabolic state after ingestion of EAC at both 1 and $3 \mathrm{~h}$ postexercise (21). Similarly, in the present study, it is likely that the increase in NB from negative to positive after EAC consumption in both trials was also primarily due to an increase in muscle protein synthesis. Mean $R_{d}$, i.e., uptake of amino acids from the plasma pool, increased dramatically (216 and $200 \%$ for PRE and POST, respectively) after ingestion of EAC. The fact that phenylalanine $R_{a}$, an indicator of muscle protein breakdown, did not change in response to EAC ingestion further supports the notion that the change of net muscle protein balance from positive to negative is primarily due to an increase in protein synthesis.

In the present study, our arteriovenous tracer methodology has quantified only the fate of blood-borne amino acids $(25,29)$. Because the incorporation of amino acids from the EAC solution into muscle protein was of primary interest, $R_{d}$ and $R_{a}$ calculated using blood-borne amino acids seemed the most appropriate measures. In past studies we have utilized a threecompartment model of muscle protein metabolism to describe the effects of nutrition and exercise on muscle protein synthesis and breakdown $(3,5,6,14,15,27)$. However, in the present study, the combination of sampling in close proximity to exercise and a bolus ingestion of amino acids has made the use of that model problematic. That model requires an isotopic and physiological steady state, as well as a measurable gradient between blood and intracellular phenylalanine enrichment. Instead, we calculated $R_{a}$ and $R_{d}$ by use of data only from blood $(25,29)$. Whereas care must be taken in interpreting $R_{\mathrm{a}}$ and $R_{\mathrm{d}}$ values from this model $(3,30)$, it is the appropriate model to use in the present study. The importance of the plasma amino acids as a source for muscle protein synthesis is emphasized in this study. Therefore utilization of $R_{d}$ was the appropriate parameter with which to compare the effects of the timing of ingestion of the EAC drink. Moreover, utilization of the blood-borne precursor for measurement of $R_{d}$ allows us to relate these values to net muscle protein synthesis determined by phenylalanine uptake.

The ingestion of a relatively small amount of essential amino acids, combined with carbohydrates, is an effective stimulator of net muscle protein synthesis. The stimulation of net muscle protein synthesis when EAC is consumed before exercise is superior to that when EAC is consumed after exercise. The combination of increased amino acid levels at a time when blood flow is increased appears to offer the maximum stimulation of muscle protein synthesis by increasing amino acid delivery to the muscle and thus amino acid availability.

We thank the nurses and staff of the General Clinical Research Center (GCRC) at the University of Texas Medical Branch in Galveston, TX. We also thank Dr. J. Rosenblatt for statistical assistance, and the volunteers who participated in the studies for their time and hard work.

This work was supported in part by Grants 8940 and 15489 from the Shriners Hospitals for Children and National Institutes of Health (NIH) Grant R01-38010. Studies were conducted at the GCRC at the University of Texas Medical Branch at Galveston, which is funded by a grant (M01 RR-00073) from the National Center for Research Resources, NIH.

\section{REFERENCES}

1. Bennet WM, Connacher AA, Scrimgeour CM, Smith K, and Rennie MJ. Increase in anterior tibialis muscle protein synthesis in healthy man during mixed amino acid infusion: studies of incorporation of $\left[1{ }^{13} \mathrm{C}\right]$ leucine. Clin Sci (Colch) 76: 447-454, 1989.

2. Bergström J, Furst P, Noree LO, and Vinnars E. Intracellular free amino acid concentration in human muscle tissue. J Appl Physiol 36: 693-697, 1974.

3. Biolo G, Chinkes D, Zhang XJ, and Wolfe RR. Harry M. Vars Research Award. A new model to determine in vivo the relationship between amino acid transmembrane transport and protein kinetics in muscle. J Parenter Enteral Nutr 16: 305-315, 1992.

4. Biolo G, Fleming RY, Maggi SP, and Wolfe RR. Transmembrane transport and intracellular kinetics of amino acids in human skeletal muscle. Am J Physiol Endocrinol Metab 268: E75-E84, 1995.

5. Biolo G, Maggi SP, Williams BD, Tipton KD, and Wolfe RR. Increased rates of muscle protein turnover and amino acid transport after resistance exercise in humans. Am J Physiol Endocrinol Metab 268: E514-E520, 1995.

6. Biolo G, Tipton KD, Klein S, and Wolfe RR. An abundant supply of amino acids enhances the metabolic effect of exercise on muscle protein. Am J Physiol Endocrinol Metab 273: E122E129, 1997.

7. Biolo G, Williams BD, Fleming RY, and Wolfe RR. Insulin action on muscle protein kinetics and amino acid transport during recovery after resistance exercise. Diabetes 48: 949-957, 1999.

8. Bylund-Fellenius AC, Ojamaa KM, Flaim KE, Li JB, Wassner SJ, and Jefferson LS. Protein synthesis versus energy state in contracting muscles of perfused rat hindlimb. Am J Physiol Endocrinol Metab 246: E297-E305, 1984.

9. Carraro F, Stuart CA, Hartl WH, Rosenblatt J, and Wolfe RR. Effect of exercise and recovery on muscle protein synthesis in human subjects. Am J Physiol Endocrinol Metab 259: E470E476, 1990.

10. Dempster WT and Gaughran GRL. Properties of body segment based on size and weight. Am J Anat 120: 33-54, 1965.

11. Farrell PA, Fedele MJ, Vary TC, Kimball SR, Lang CH, and Jefferson LS. Regulation of protein synthesis after acute resistance exercise in diabetic rats. Am J Physiol Endocrinol Metab 276: E721-E727, 1999.

12. Fedele MJ, Hernandez JM, Lang CH, Vary TC, Kimball SR, Jefferson LS, and Farrell PA. Severe diabetes prohibits elevations in muscle protein synthesis after acute resistance exercise in rats. J Appl Physiol 88: 102-108, 2000.

13. Ferrando AA, Tipton KD, Doyle D, Phillips SM, Cortiella J, and Wolfe RR. Testosterone injection stimulates net protein synthesis but not tissue amino acid transport. Am J Physiol Endocrinol Metab 275: E864-E871, 1998. 
14. Fluckey JD, Vary TC, Jefferson LS, and Farrell PA. Augmented insulin action on rates of protein synthesis after resistance exercise in rats. Am J Physiol Endocrinol Metab 270: E313-E319, 1996.

15. Forslund AH, Hambraeus L, Olsson RM, El-Khoury AE, Yu YM, and Young VR. The 24-h whole body leucine and urea kinetics at normal and high protein intakes with exercise in healthy adults. Am J Physiol Endocrinol Metab 275: E310E320, 1998

16. Gannon MC, Nuttall FQ, Krezowski PA, Billington CJ, and Parker S. The serum insulin and plasma glucose response to milk and fruit products in type 2 (non-insulin-dependent) diabetic patients. Diabetolgia 29: 784-791, 1986.

17. Hernandez JM, Fedele MJ, and Farrell PA. Time course evaluation of protein synthesis and glucose uptake after acute resistance exercise in rats. J Appl Physiol 88: 1142-1149, 2000.

18. Meredith CN, Frontera WR, Fisher EC, Hughes VA, Herland JC, Edwards J, and Evans WJ. Peripheral effects of endurance training in young and old subjects. J Appl Physiol 66: 2844-2849, 1989.

19. Phillips SM, Tipton KD, Aarsland A, Wolf SE, and Wolfe RR. Mixed muscle protein synthesis and breakdown after resistance exercise in humans. Am J Physiol Endocrinol Metab 273: E99-E107, 1997.

20. Phillips SM, Tipton KD, Ferrando AA, and Wolfe RR. Resistance training reduces the acute exercise-induced increase in muscle protein turnover. Am J Physiol Endocrinol Metab 276: E118-E124, 1999.

21. Rasmussen BB, Tipton KD, Miller SL, Wolf SE, and Wolfe RR. An oral essential amino acid-carbohydrate supplement enhances muscle protein anabolism after resistance exercise. J Appl Physiol 88: 386-392, 2000.
22. Rennie MJ, Edwards RH, Krywawych S, Davies CT, Halliday D, Waterlow JC, and Millward DJ. Effect of exercise on protein turnover in man. Clin Sci (Colch) 61: 627-639, 1981.

23. Rosenblatt J, Chinkes D, Wolfe M, and Wolfe RR. Stable isotope tracer analysis by GC-MS, including quantification of isotopomer effects. Am J Physiol Endocrinol Metab 263: E584E596, 1992

24. Smith K, Reynolds N, Downie S, Patel A, and Rennie MJ. Effects of flooding amino acids on incorporation of labeled amino acids into human muscle protein. Am J Physiol Endocrinol Metab 275: E73-E78, 1998.

25. Thompson GN, Pacy PJ, Ford GC, and Halliday D. Practical considerations in the use of stable isotope labelled compounds as tracers in clinical studies. Biomed Environ Mass Spectrom 18: 321-327, 1989.

26. Thompson GN, Pacy PJ, Merritt H, Ford GC, Read MA, Cheng KN, and Halliday D. Rapid measurement of whole body and forearm protein turnover using a $\left[{ }^{2} \mathrm{H}_{5}\right]$ phenylalanine model. Am J Physiol Endocrinol Metab 256: E631-E639, 1989.

27. Tipton KD, Ferrando AA, Phillips SM, Doyle D Jr, and Wolfe RR. Postexercise net protein synthesis in human muscle from orally administered amino acids. Am J Physiol Endocrinol Metab 276: E628-E634, 1999.

28. Tipton KD, Gurkin BE, Matin S, and Wolfe RR. Nonessential amino acids are not necessary to stimulate net muscle protein synthesis in healthy volunteers. J Nutr Biochem 10: 89-95, 1999.

29. Wolfe RR. Radioactive and Stable Isotope Tracers in Biomedicine: Principles and Practice of Kinetic Analysis. New York: Wiley-Liss, 1992.

30. Wolfe RR. Effects of insulin on muscle tissue. Curr Opin Clin Nutr Metab Care 3: 67-71, 2000.

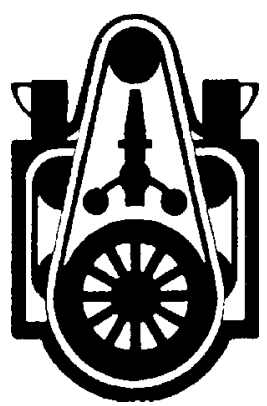

